\title{
Effect of the silica content of diatom prey on the production, decomposition and sinking of fecal pellets of the copepod Calanus sinicus
}

\author{
Hongbin Liu and Chih-Jung Wu \\ Division of Life Science, The Hong Kong University of Science and Technology, Clear Water Bay, Kowloon, Hong Kong \\ Correspondence to: Hongbin Liu (liuhb@ust.hk)
}

Received: 22 April 2016 - Published in Biogeosciences Discuss.: 2 May 2016 Revised: 18 July 2016 - Accepted: 25 July 2016 - Published: 23 August 2016

\begin{abstract}
The effects of changing the amount of silica in the cell wall of diatom prey, on the production, decomposition rate and sinking velocity of fecal pellets of the calanoid copepod, Calanus sinicus, were examined. Using different light intensities to control the growth of the diatom Thalassiosira weissflogii also led to the accumulation of different amounts of biogenic silica. Copepods were then fed either low $\left(\sim 1600\right.$ cells $\left.\mathrm{L}^{-1}\right)$ or high $\left(\sim 8000\right.$ cells $\left.\mathrm{L}^{-1}\right)$ concentrations of this diatom. Copepods fed a high concentration of diatoms with high-silica content exhibited a lower grazing rate and lower fecal pellet production rate than those fed a high concentration of diatoms with low-silica content. However, there was no difference in either the grazing or fecal pellet production rates at low prey concentrations with high- or low-silica content. The size of the fecal pellets produced was only affected by the prey concentration, and not by the silica content of prey. In addition, the degradation rate of the fecal pellets was much higher for copepods fed a low-silica diet than for those fed a high-silica diet. Significantly lower densities and sinking rates only occurred in the fecal pellets of copepods fed a low-silica diet and a low prey concentration. Calculating the $\mathrm{L}$ ratio (the ratio of degradation rate : sinking rate) for each group indicated that the fecal pellets produced by copepods fed highly silicified diatoms are likely to transport both biogenic silica and organic carbon to the deep layer, whereas those produced following the consumption of lowsilica diatoms are likely to decompose in the mixing layer.
\end{abstract}

\section{Introduction}

In the marine environment, zooplankton fecal pellets constitute a main vehicle for transporting biogenic elements to the sediments, although a substantial proportion of this flux is recycled or repackaged in the water column by microbial decomposition and zooplankton coprophagy (Turner, 2002, 2015). Diatoms are among the most abundant phytoplankton, and they represent a main component in the diet of zooplankton in marine environments. Studies show that zooplankton with a diatom diet usually produce fecal pellets that sink faster than those on other diets (Feinberg and Dam, 1998). Dagg et al. (2003) reported that the contribution of fecal pellets to the flux of particulate organic carbon (POC) and biogenic silica $(\mathrm{bSi})$ is higher during the spring diatom bloom than during the summer within the Antarctic Polar Front region. Similarly, Goldthwait and Steinberg (2008) reported an increase in mesozooplankton biomass and fecal production and flux inside cyclonic and mode-water eddies. However, González et al. (2007) reported a negative correlation between the vertical carbon flux of diatoms and the production of fecal material in a time-series study in the upwelling waters off Chile.

The quantity and characteristics of the fecal pellets produced by zooplankton depend on several factors. The pellet production rate is reported to be affected by the rate of ingestion and assimilation efficiency (Butler and Dam, 1994; Besiktepe and Dam, 2002). It has also been demonstrated that the type of diet can affect the characteristics of the fecal pellets produced - including size, density and sinking rates (e.g., Feinberg and Dam, 1998, and references therein). In addition, the decomposition rate of pellets varies with wa- 
ter temperature, as well as with both microbial and metazoan activity (Poulsen and Iversen, 2008; Svensen et al., 2012). Factors that contribute to the sinking velocity of the pellets include size, density and shape, all of which can vary dramatically both among different zooplankton species and within the same zooplankton species feeding on different types of prey (Fowler and Small, 1972; Turner, 1977; Feinberg and Dam, 1998). Turbulence in the water column, the presence or absence of a peritrophic membrane, and the production of microbial gas within a peritrophic membrane might also affect the sinking rate of pellets (Honjo and Roman, 1978; Bathmann et al., 1987). Indeed, the sinking rate and decomposition rate are the two most important parameters used, to determine whether a pellet will or will not be successfully transported into deeper water before its contents are degraded. For example, a slowly sinking pellet is more likely to decompose and become part of the recycled materials before it exits the euphotic zone (Dagg and Walser, 1986).

The cell wall (frustrule) of diatoms is composed of two silicate shells, which are believed to act as a defense mechanism to prevent ingestion by grazers (Pondaven et al., 2007); thus different levels of silicification of the frustrule might affect the grazing rate of copepods (Friedrichs et al., 2013, Liu et al., 2016). The silica content of the cell wall of diatoms is not only species-specific, but it is also affected by environmental parameters such as light, temperature, salinity, $\mathrm{pH}$, nutrients and trace metals (Martin-Jézéquel et al., 2000, and references therein; Claquin et al., 2002; Vrieling et al., 2007; Herve et al., 2012; Liu et al., 2016). Although the frustule has no nutritional value for zooplankton, it is thought to provide ballast, which is especially advantageous when the fecal pellets are sinking. Hence, pellets with a high diatom biomass generally exhibit higher levels of export of POC (Armstrong et al., 2002; François et al., 2002; Klaas and Archer, 2002). Thus, the content of the zooplankton diet (and therefore the type and concentration of ballast minerals ingested) might strongly affect the sinking velocity of the fecal pellets produced, and hence the vertical flux of biogenic silica and carbon.

Most of the studies describing the production rates and characteristics of copepod fecal pellets have focused on aspects such as food types (Feinberg and Dam, 1998), or the different periods of phytoplankton blooms (Butler and Dam, 1994). There are currently no reports that describe the effect of the silica content of diatoms on the production, degradation and sinking of fecal pellets. Liu et al. (2016) recently demonstrated that the diatom Thalassiosira weissflogii, when grown at different light levels, contains varying amounts of silica and that the small calanoid copepod Parvocalanus crassirostris, when fed diatoms containing high levels of silica, exhibited a reduced feeding rate and stagnant growth, as well as low egg production and hatching success. In this study we used the same diatom species with different silica content as prey to study the characteristics of the fecal pellets produced by the herbivorous copepod, Calanus sinicus.

\section{Materials and methods}

\subsection{Copepod and prey culture conditions}

The herbivorous copepod Calanus sinicus was collected from the coastal waters around Hong Kong in February 2013. Copepods were maintained on a $14 \mathrm{~h}$ light : $10 \mathrm{~h}$ dark cycle at $23.5^{\circ} \mathrm{C}$ in $2 \mathrm{~L}$ glass containers with $0.2 \mu \mathrm{m}$ filtered seawater. The copepods were fed a mixed algal diet consisting of Rhodomonas sp. and Thalassiosira weissflogii at a concentration of $\sim 5000$ cells $\mathrm{L}^{-1}$; this food suspension was supplied to the cultures twice a week and the whole culture seawater was replaced every week. The copepods were maintained for more than 1 month prior to the start of the experiment to ensure that all the adults were grown in approximately the same conditions and were of approximately the same age.

The diatom $T$. weissflogii was maintained in exponential growth in f/2 medium (Guillard, 1975), under light intensities of either 15 or $200 \mu \mathrm{mol}$ photons $\mathrm{s}^{-1} \mathrm{~m}^{-2}$ to generate cells with different cellular silica contents (Liu et al., 2016). The diatom cultures were transferred every 4 or 8 days for the high- and low-light batches, respectively. After two transfers the amount of biogenic silica in the diatom cells was measured using a modified version of the method described by Paasche (1980), following the procedures described more recently by Grasshoff et al. (1999). Cells were collected on a $1 \mu \mathrm{m}$ polycarbonate filter ( $47 \mathrm{~mm}$ diameter) and washed with $10 \mathrm{~mL}$ autoclaved seawater and $0.01 \mathrm{M} \mathrm{HCl}$ during filtration to remove the intercellular silicate pools. The folded filter was immediately placed into a $15 \mathrm{~mL}$ polypropylene tube and stored at $-80^{\circ} \mathrm{C}$. Hydrolysis was carried out using $4 \mathrm{~mL}$ of $5 \% \mathrm{NaOH}$, digested at $85^{\circ} \mathrm{C}$ for $2 \mathrm{~h}$. After cooling, $0.72 \mathrm{~mL}$ of $1.0 \mathrm{M} \mathrm{HCl}$ was added to each tube, lowering the $\mathrm{pH}$ to 3-4. Silicic acid concentration of samples was determined colorimetrically, through the formation of blue-colored silica complexes.

\subsection{Experimental design}

Active adult female Calanus sinicus specimens with intact appendages were selected and starved for $24 \mathrm{~h}$ before an experiment. A total of seven experiments were conducted to determine fecal pellet production, degradation and sinking, and in each experiment these parameters were measured both at low and high food concentrations, and at high and low levels of silica contained in the diatom prey (Table 1). In each experiment, the copepods were fed the same species of diatom (i.e., T. weissflogii), at either ca. 1600 cells L $^{-1}$ (low concentration) or ca. 8000 cell L$^{-1}$ (high concentration), the latter being above the food saturation level according to Frost (1972). The abundance and volume of diatoms were measured (triplicate subsamples) using a Beckman Coulter Z2 particle counter and size analyzer.

In the fecal pellet production experiments, five replicate bottles containing one copepod per bottle and two control 
Table 1. Summary of the concentration and cellular silica content of the diatom prey in each experiment.

\begin{tabular}{|c|c|c|c|c|c|}
\hline Experiment & Measurements & [Prey] & $\begin{array}{l}\text { Silica } \\
\text { level }\end{array}$ & $\begin{array}{l}\text { Initial prey density } \\
\left(\text { cells } \mathrm{mL}^{-1}\right)\end{array}$ & $\begin{array}{l}\text { Cellular silica } \\
\left(\mathrm{pg} \mathrm{SiO}_{2} \text { cell }^{-1}\right)\end{array}$ \\
\hline \multirow[t]{2}{*}{1} & \multirow{4}{*}{$\begin{array}{l}\text { Fecal pellet } \\
\text { production }\end{array}$} & High & High & $8194 \pm 166.9$ & $55.7 \pm 1.7$ \\
\hline & & High & Low & $7976 \pm 8.5$ & $38.2 \pm 1.4$ \\
\hline \multirow[t]{2}{*}{2} & & Low & High & $1640 \pm 28.3$ & $51.7 \pm 1.9$ \\
\hline & & Low & Low & $1490 \pm 84.9$ & $31.4 \pm 6.6$ \\
\hline \multirow[t]{2}{*}{3} & \multirow{6}{*}{$\begin{array}{l}\text { Fecal pellet } \\
\text { degradation* }\end{array}$} & High & High & $8194 \pm 166.9$ & $55.7 \pm 1.7$ \\
\hline & & High & Low & $7976 \pm 8.5$ & $38.2 \pm 1.4$ \\
\hline \multirow[t]{2}{*}{4} & & High & High & $7499 \pm 63.6$ & $58.9 \pm 2.4$ \\
\hline & & High & Low & $7344 \pm 169.7$ & $33.4 \pm 4.3$ \\
\hline \multirow[t]{2}{*}{5} & & Low & High & $1640 \pm 28.3$ & $51.7 \pm 1.9$ \\
\hline & & Low & Low & $1490 \pm 84.9$ & $31.4 \pm 6.6$ \\
\hline \multirow[t]{2}{*}{6} & \multirow{4}{*}{$\begin{array}{l}\text { Fecal pellet } \\
\text { sinking }\end{array}$} & High & High & $8114 \pm 138.0$ & $56.5 \pm 5.9$ \\
\hline & & High & Low & $7904 \pm 124.7$ & $27.0 \pm 0.6$ \\
\hline \multirow[t]{2}{*}{7} & & Low & High & $1790 \pm 48.1$ & $52.1 \pm 1.3$ \\
\hline & & Low & Low & $1545 \pm 75.0$ & $30.3 \pm 3.1$ \\
\hline
\end{tabular}

* The incubation time of the three fecal pellet degradation experiments can be found in Table 3 .

Table 2. Degradation rate of the fecal pellets produced by $C$. sinicus after they were fed diatoms with different silica content.

\begin{tabular}{lllcc}
\hline $\begin{array}{l}\text { Prey } \\
\text { concentration }\end{array}$ & $\begin{array}{l}\text { Incubation } \\
\text { period }\end{array}$ & $\begin{array}{l}\text { Silicon status } \\
\text { of prey }\end{array}$ & $n$ & $\begin{array}{l}\text { Degradation } \\
\text { rate }\left(\text { day }^{-1}\right)\end{array}$ \\
\hline High & $48 \mathrm{~h}$ & $\mathrm{HSi}$ & 3 & $0.21 \pm 0.15$ \\
& & $\mathrm{LSi}$ & 3 & $0.91 \pm 0.17$ \\
\hline High & $24 \mathrm{~h}$ & $\mathrm{HSi}$ & 4 & $0.03 \pm 0.04$ \\
& & $\mathrm{LSi}$ & 4 & $0.15 \pm 0.02$ \\
\hline Low & $24 \mathrm{~h}$ & $\mathrm{HSi}$ & 3 & $0.08 \pm 0.04$ \\
& & LSi & 2 & $0.38 \pm 0.03$ \\
\hline
\end{tabular}

Note: HSi: high silica content, LSi: low silica content.

bottles without a grazer were used. All the bottles were filled with $100 \mathrm{~mL}$ freshly prepared media consisting of $0.2 \mu \mathrm{m}$ prefiltered seawater and suspensions of the respective prey for each treatment. All incubations were conducted at $23.5^{\circ} \mathrm{C}$ and in the dark for $24 \mathrm{~h}$. At the end of the incubation period, a $2 \mathrm{~mL}$ sample was collected from each bottle and fixed with acid Lugol's at a final concentration of $2 \%$, for subsequent diatom quantification. The remaining water was collected in a $50 \mathrm{~mL}$ polypropylene tube and fixed with glutaraldehyde at a final concentration of $1 \%$, for further quantification of the fecal pellets.

In order to obtain fresh pellets for the degradation experiments, two plastic beakers were prepared for the high- and low-silica content prey. Each beaker contained 7-8 copepods and $700 \mathrm{~mL}$ culture medium, prepared as described for the production experiments. After $12 \mathrm{~h}$ of incubation (except for experiment 3, which was incubated for $18 \mathrm{~h}$ ), the medium was sieved through a $40 \mu \mathrm{m}$ mesh to collect the fecal pellets and then rinsed with autoclaved $0.22 \mu \mathrm{m}$ filtered seawa- ter. At least 20 intact fecal pellets were selected using a glass Pasteur pipette under a stereomicroscope and poured into a $250 \mathrm{~mL}$ polycarbonate bottle containing $200 \mathrm{~mL}$ of $2 \mu \mathrm{m}$ prefiltered sea water taken from the field. The number of replicate bottles and the incubation period of each experiment are shown in Table 2. All the bottles were put on a roller at $0.4 \mathrm{rpm}$ in the dark at $23.5^{\circ} \mathrm{C}$; then at the end of the respective incubation times, the whole water of each bottle was collected in a plastic bottle and fixed with glutaraldehyde at a final concentration of $1 \%$ for further fecal pellet analysis.

Experiments to estimate the fecal pellet sinking rate were conducted by obtaining fecal pellets using the degradation experiment procedure (described above) but with an incubation time of $24 \mathrm{~h}$. After collecting all the fecal pellets from the beakers, 50 intact pellets were selected and suspended in $260 \mathrm{~mL} 0.2 \mu \mathrm{m}$ prefiltered autoclaved seawater. The fecal pellet sinking rate was measured using a SETCOL chamber ( $49 \mathrm{~cm}$ height, $2.6 \mathrm{~cm}$ inner diameter) made by $4 \mathrm{~mm}$ Plexiglas (Bienfang, 1981), filled with well-mixed pelletcontaining seawater. The chamber was allowed to settle for $6 \mathrm{~min}$, and then the whole column of water was collected from outflow tubes in a top-to-bottom order. The water was collected in a plastic bottle and fixed with glutaraldehyde as described above, for subsequent fecal pellet analysis.

\subsection{Determining the number and size of fecal pellets}

The water samples containing the fecal pellets in the $50 \mathrm{~mL}$ polypropylene tubes were allowed to settle for $24 \mathrm{~h}$. The upper water was then removed smoothly and the remainder was poured into the well of a six-well plate and the number of pellets was counted using an inverted microscope (Olympus IX51) at $100 \times$ magnification. Only intact fecal pellets and 
fragments with end points were counted. The total number of fecal pellets was then calculated to include all of the intact fecal pellets plus half of the pellet fragments. Images of at least 30 intact fecal pellets were acquired with a CCD camera (Model 4.2, Diagnostic Instrument Inc., USA), after which the length and width of each fecal pellet were measured, and the volume was calculated assuming that they are cylindrical in shape.

\subsection{Calculating the fecal pellet degradation rate}

The rate of degradation of the fecal pellets was calculated from the loss of fecal pellet equation, described by

$N_{t}=N_{0} e^{-r t}$,

where $N$ is the total number of fecal pellets in the incubation bottle at the beginning $\left(N_{0}\right)$ and end of the experiment $\left(N_{t}\right)$; $t$ is the incubation time (in days); and $r$ is the degradation rate $\left(\mathrm{d}^{-1}\right)$. The degradation rate estimated in this study only considered the effect of microbial organisms and assumed that the loss rate was exponential.

\subsection{Calculating the fecal pellet sinking velocity}

The rate that fecal pellets sank was calculated from the formula reported by Bienfang et al. (1982), which was originally used to measure the average sinking rate of phytoplankton. Thus,

$S=\frac{N_{\mathrm{s}}}{N_{\mathrm{t}}} \times \frac{L}{t}$,

where $S$ is the average sinking velocity; $L$ is the height of the sinking column; $t$ is the duration of the trial; $N_{\mathrm{t}}$ is the total number of fecal pellets within the settling water volume; and $N_{\mathrm{S}}$ is the total number of fecal pellets that settled during the trial time.

In addition, the density of the fecal pellets was calculated using the semi-empirical equation deduced by Komar (1980), as follows:

$w_{\mathrm{s}}=0.079 \frac{1}{\mu}\left(\rho_{s}-\rho\right) g L^{2}\left(\frac{L}{D}\right)^{-1.664}$,

where $w_{\mathrm{s}}$ is the sinking velocity of the fecal pellets; $\mu$ and $\rho$ are the fluid viscosity and density, respectively; $L$ and $D$ are the length and diameter of the fecal pellets, respectively, assuming they are in the cylindrical shape; $g$ is the acceleration of gravity; and $\rho_{s}$ is the density of fecal pellet.

\section{Results}

\subsection{Grazing response}

The cellular silica content of first- and second-generation $T$. weissflogii when cultured at high and low light intensities is

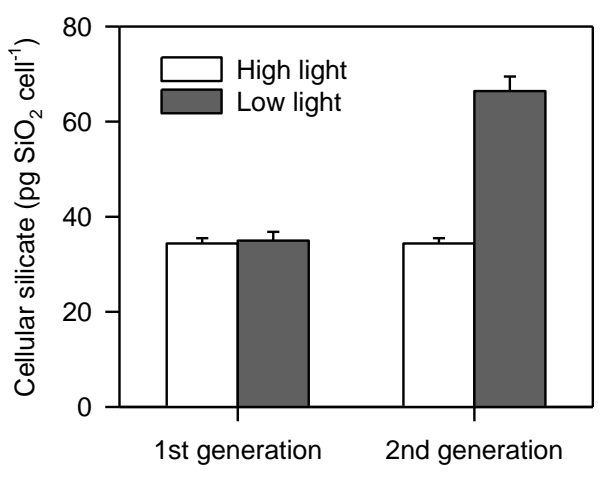

Figure 1. The cellular silica content of T. weissflogii grown under different light intensities. The error bars show 1 standard deviation $(n=3)$.

shown in Fig. 1. After two transfers the cellular biogenic silica content was significantly different $(t$ test, $p<0.05$; Fig. 1) when comparing the high-light and low-light culture conditions. The silica content of high- and low-silica diatoms used in all the experiments was consistent, and the differences between the two treatments were all statistically significant (Table 1). Other cellular parameters, such as cell size and carbon and nitrogen contents, were also measured for selected samples (data not shown), and the results were consistent with those reported in a previous study (Liu et al., 2016), which showed no significant difference between the two types of prey.

The grazing response of $C$. sinicus to diatoms with different silica contents showed similar patterns between high (ca. 8000 cells $\mathrm{mL}^{-1}$ ) and low (ca. 1600 cells $\mathrm{mL}^{-1}$ ) prey concentration (Fig. 2). At high concentrations of prey, $C$. sinicus grazed the diatoms with low cellular silica content 2 times faster than when they had a high silica content ( $t$ test, $p<0.05$ ). The same trend was also observed at low concentrations of the prey, although in this case the difference was not statistically significant. In addition, the rate of clearance was significantly higher for the low-silica prey than for the high-silica prey at both low and high prey concentrations $(t$ test, $p<0.05)$. These results indicate that the silica content of diatoms can affect the grazing activity of copepods.

\subsection{Fecal pellet production}

The rate of fecal pellet production varied both with the silica content and the concentration of the prey (Fig. 3a). At a high prey concentration, $C$. sinicus that were fed low-silica prey produced significantly higher amounts of fecal pellets $\left(192 \pm 32 \mathrm{FP} \mathrm{ind}^{-1} \mathrm{~d}^{-1}\right)$ than those fed high-silica prey $\left(113 \pm 47 \mathrm{FP}\right.$ ind $\left.^{-1} \mathrm{~d}^{-1}, \mathrm{p}<0.05\right)$, which corresponds well with the rate of ingestion (Figs. $2 \mathrm{a}$ and $3 \mathrm{a}$ ). At a low prey concentration, however, the production of fecal pellets by $C$. sinicus fed the low- and high-silica prey was not significantly different (Fig. 3a). In addition, the size of the fecal pellets 

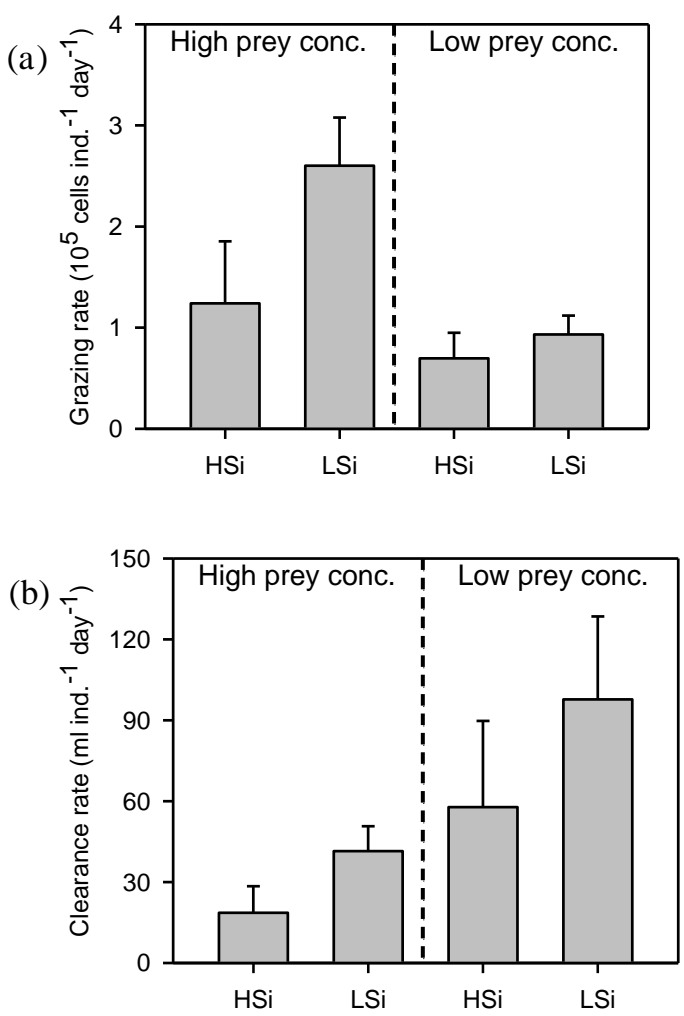

Figure 2. Grazing rate (a) and clearance rate (b) of $C$. sinicus fed high and low concentration of diatoms with different silica content. HSi and LSi are high- and low-silica diatom prey, respectively. The error bars show 1 standard deviation $(n=5)$.

was only affected by the concentration of the prey, and not by the silica content of the prey (Fig. 3b). Thus, the fecal pellets produced in the high concentration of prey groups had a mean length and width of $582.4 \pm 98.7$ and $72.5 \pm 4.5 \mu \mathrm{m}$, respectively, which are significantly larger than the size of those produced in the low concentration of prey groups, which had an average length and width of $352.4 \pm 54.7$ and $59.6 \pm 6.8 \mu \mathrm{m}$, respectively (ANOVA, $p<0.05$ ).

\subsection{Fecal pellet degradation rate and sinking rate}

The degradation rate of fecal pellets was significantly different when the copepods fed diatoms with different silica content (Table 2). The degradation rate of the fecal pellets produced from the low-silica prey was approximately 4-5-fold higher than that of the pellets generated from the high-silica prey, irrespective of the prey concentration or the period of degradation incubation. In addition, the degradation rate of the fecal pellets from low prey concentration was significantly higher than ones from high prey concentration after an incubation period of $24 \mathrm{~h}(p<0.05$, ANOVA). Furthermore, the degradation rate obtained following $48 \mathrm{~h}$ incubation was significantly higher than that following just $24 \mathrm{~h}$ incubation (only high prey concentration experiments) for both the high-
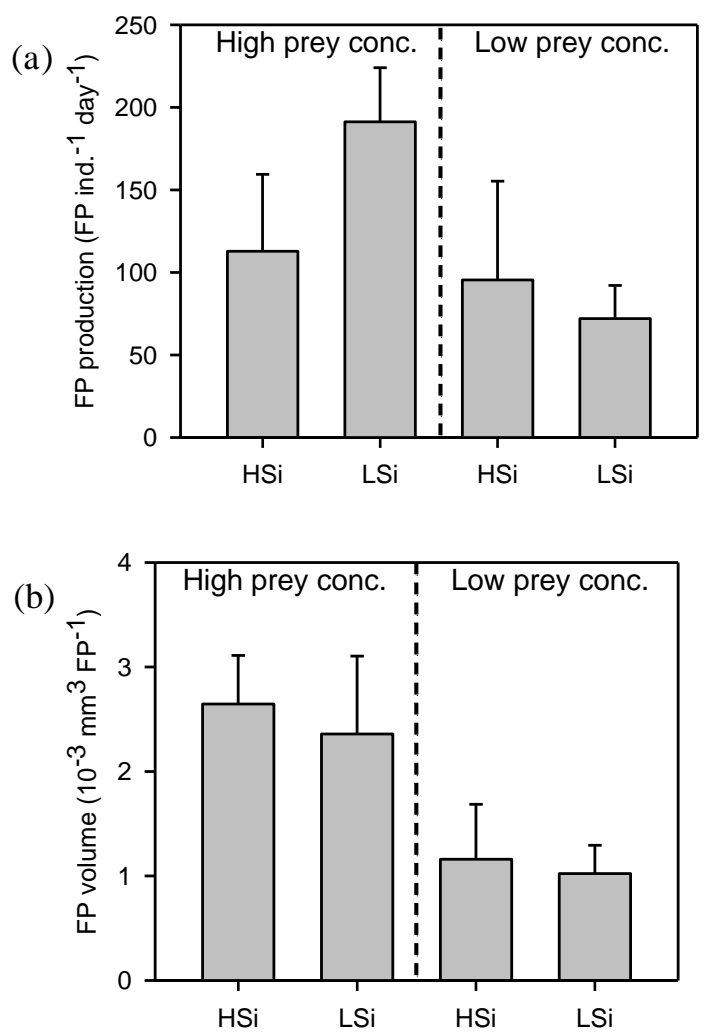

Figure 3. Production rate (a) and average volume (b) of fecal pellet produced by $C$. sinicus fed different concentration of diatom prey. HSi and LSi indicate high- and low-silica diatom prey, respectively. The error bars show 1 standard deviation $(n=5)$.

silica ( $p<0.05, t$ test) and low-silica ( $p$ textless $0.01, t$ test) prey (Table 2), indicating an acceleration of degradation on the second day of incubation.

The sinking rate of fecal pellets was also different for the high and low prey concentrations (Fig. 4). At a high concentration of prey, the sinking rates of the pellets produced by the high- and low-silica prey (i.e., 3.05 and $3.13 \mathrm{~cm} \mathrm{~min}^{-1}$, respectively) were not significantly different. However, at a low prey concentration, the sinking rate of pellets from the high-silica-content prey (i.e., $2.59 \mathrm{~cm} \mathrm{~min}^{-1}$ ) was significantly greater ( $t$ test, $p<0.01)$ than that of pellets from the low-silica-content prey (i.e., $0.53 \mathrm{~cm} \mathrm{~min}^{-1}$ ). The average density of the fecal pellets was calculated as being 1.093$1.095 \mathrm{~g} \mathrm{~cm}^{-3}$ at the high prey concentration and 1.035 $1.097 \mathrm{~g} \mathrm{~cm}^{-3}$ at the low prey concentration. The variation in the calculated density of fecal pellets is consistent with the pattern of sinking rate, with the lowest density occurring in fecal pellets from low-silica prey at the low prey concentration (Fig. 4). 


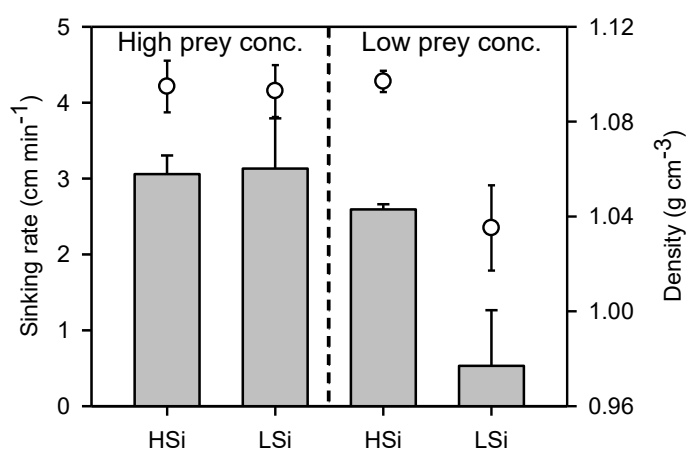

Figure 4. The sinking rate (bars) and calculated density (open dots) of the fecal pellets generated by $C$. sinicus following each treatment. HSi and LSi are high- and low-silica diatom prey, respectively. The error bars show 1 standard deviation $(n=3)$.

\section{Discussion}

The grazing activity of copepods varies not only with the concentration of the prey but also with the nutritional quality of the prey. In our study, the grazing and clearance rates determined with varying food concentrations followed a similar trend to that described in the literature (e.g., Frost, 1972). In addition, the grazing activity was affected by the cellular silica content of the prey, as has been observed with other copepod species (Liu et al., 2016). Silicification has been suggested to be one of the strategies that is used by diatoms to protect them from ingestion by grazers (Pondaven et al., 2007). Friedrichs et al. (2013) examined the mechanical strength of the frustules of three diatom species and measured the feeding efficiency of copepods on these diatoms. Their results showed that the diatom species with the more weakly silicified frustules and the highest growth rate was the least stable and was fed upon the most, whereas the species with the most complex frustule exhibited the greatest stability and was fed upon the least. Within the same species of diatom, different growth rates have resulted in different amounts of silica in the frustule (Claquin et al., 2002). This results in higher copepod ingestion and clearance rates for diatoms with a low silica content when compared with those for diatoms with a higher silica content (Liu et al., 2016). The results obtained in the current study are consistent with those reported by Friedrichs et al. (2013) and Liu et al. (2016).

Previous studies indicate that while there is a linear relationship between the ingestion rate and the total number of fecal pellets produced per unit time (Ayukai and Nishizawa, 1986; Ayukai, 1990), there is a high level of variation among different diets (Båamstedt et al., 1999, and references therein; Besiktepe and Dam, 2002). In addition, the size of fecal pellets increases as the concentration of the food increases, such that they reach a maximum size when the concentration of food is above the saturation level (Dagg and Walser, 1986; Butler and Dam, 1994). Our results confirmed these previous

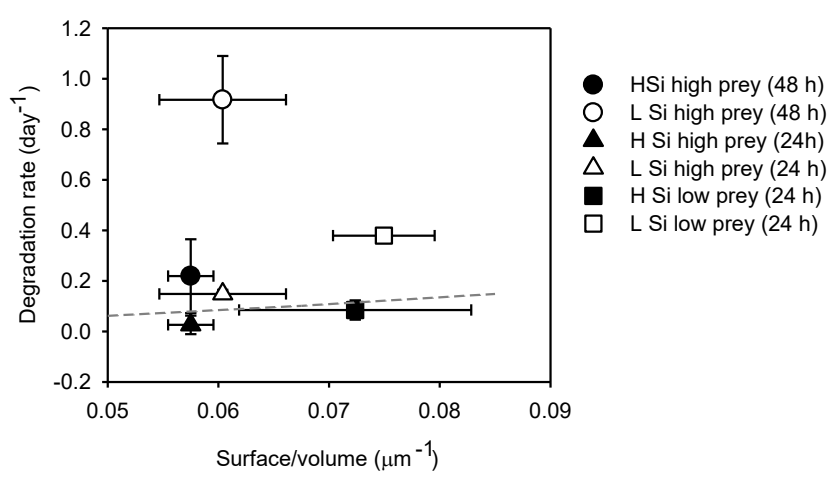

Figure 5. The relationship between degradation rates and surface : volume ratio of fecal pellets from different experimental treatments. HSi and LSi are high- and low-silica-content diatoms, respectively; high and low prey are high and low prey concentrations, respectively; 48 and $24 \mathrm{~h}$ are the incubation periods used for the degradation experiments. The error bars show \pm 1 standard deviation, and the dashed line shows the relationship curve generalized by Olesen et al. (2005).

findings and demonstrated that the size of fecal pellets produced was only affected by the concentration of prey, and fecal pellets did not show any significant size differences when comparing prey of high and low cellular silica content. Butler and Dam (1994) reported that when sufficient food was available, the size of the fecal pellets varied with the nutritional quality (e.g., the $\mathrm{C}: \mathrm{N}$ ratio) of the prey. Since diatoms with different silica content (generated by varying the light intensity) do not differ in their cellular $\mathrm{C}: \mathrm{N}$ ratio (Claquin et al., 2002; Liu et al., 2016), these ratios did not affect the size of the pellets produced.

The degradation rate and sinking velocity of the fecal pellets are highly dependent on the characteristics of the pellets, which are in turn affected by the quality and quantity of the food ingested (Feinberg and Dam, 1998; Turner, 2002, 2015, and references therein). For example, it is known that the decomposition rate of the fecal pellets is affected by diet, pellet size and the producer of the pellets (e.g., Shek and Liu, 2010), but no research has addressed the degradation rates of fecal pellets produced by prey under different stoichiometric conditions. Hansen et al. (1996) estimated the degradation rate of fecal pellets produced from diets of Thalassiosira weissflogii, a diatom; Rhodomonas baltica, a nanoflagellate; or Heterocapsa triquetra, a dinoflagellate. Fecal pellets produced from a diet of the diatom species presented the slowest rate of degradation when compared with those produced from diets of the nanoflagellate or dinoflagellate species. Similarly, Olesen et al. (2005) compared the degradation rate of fecal pellets produced on a diet of the diatom, Skeletonema costatum, or the nanoflagellate, Rhodomonas salina, and reported a similar trend but higher degradation rates than Hansen et al. (1996). The relationship between the surface: volume ratio and the degradation rate 


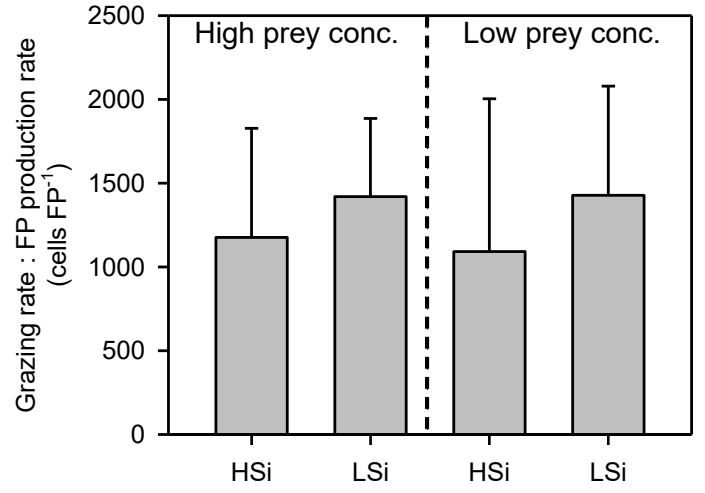

Figure 6. The grazing rate : fecal pellet production rate ratio of each treatment. HSi and LSi are the high- and low-silica diatom prey, respectively. The error bars show 1 standard deviation.

of fecal pellets was used to explain the variation in the degradation rate of pellets produced with different diets. Our results (Table 2) were higher than those reported by Hansen et al. (1996), which were $0.024 \mathrm{~d}^{-1}$ for T. weissflogii, but our results showed a similar trend to those summarized by Olesen et al. (2005) (dashed line in Fig. 5), in that there was an increase in the degradation rate with the increase in fecal pellet surface: volume ratio, although the degradation rates that we measured exceeded the predicted rates in most cases, particularly for fecal pellets produced with low-silica diatom prey (Fig. 5). The generally higher rates in our study might be caused by the higher temperature that we used when compared with the previous studies (i.e., $23.5^{\circ} \mathrm{C}$ in our study vs. 17 and $18^{\circ} \mathrm{C}$ in Olesen et al., 2005, and Hansen et al., 1996, respectively), but the differences in predator and prey quality, particularly the cellular Si content in this study, cannot be ignored.

The sinking rate of fecal pellets is usually considered to be related to their size and density, which is in turn dependent on the concentration and composition of the prey (Bienfang, 1980; Urban et al., 1993; Feinberg and Dam, 1998). We also demonstrated that fecal pellet size, sinking rate and density were correlated with the concentration of prey (Figs. 3b, 4), especially in the low-silica diatom prey treatment. Using the ratio of ingestion rate: fecal pellet production rate ratio as an index to compare the diatom content per fecal pellet, no differences were found in pellets produced from diets of the same silica content (Fig. 6), indicating that prey concentration does not affect the package content of the fecal pellets. On the other hand, copepods were shown to pack fewer hard-shelled (i.e., high-silica) diatoms into each fecal pellet in comparison to the soft-shelled (i.e., low-silica) diatoms, although these data were not significantly different statistically (Fig. 6).

The fecal pellets of copepods are formed in the midgut surrounded by a peritrophic membrane, which is believed to protect the gut wall from the sharp edges of the prey's cell
Table 3. The $\mathrm{L}$ ratio $\left(\mathrm{m}^{-1}\right)$, determined as the mean degradation rate constant $\left(\mathrm{t}^{-1}\right)$, divided by the mean sinking rate $\left(\mathrm{m} \mathrm{d}^{-1}\right)$, for each treatment.

\begin{tabular}{lll}
\hline $\begin{array}{l}\text { Prey silica } \\
\text { content }\end{array}$ & $\begin{array}{l}\text { High food } \\
\text { concentration }\end{array}$ & $\begin{array}{l}\text { Low food } \\
\text { concentration }\end{array}$ \\
\hline High Si & $3.91 \times 10^{-4}$ & $7.56 \times 10^{-4}$ \\
Low Si & $1.09 \times 10^{-3}$ & $1.65 \times 10^{-2}$ \\
\hline
\end{tabular}

wall. Moreover, the different sizes of fecal pellets with similar prey content per fecal pellet are thought to result from the decrease gut passage time with the increase of food concentration. A high prey concentration results in the food passing through the gut more quickly and results in incomplete digestion, whereas a low prey concentration allows the food to be kept in the intestinal tract for a longer time and therefore digestion is relatively more complete. We showed that the silica content of the diatom cell wall determines the density and sinking rate of the fecal pellets when the prey concentration was low due to complete digestion. In addition, we showed that only the low concentration of low-silica prey group resulted in a significantly lower fecal pellet density and sinking rate. In previous studies, the sinking rate and density of the fecal pellets of Calanus were shown to be $70-171 \mathrm{~m} \mathrm{day}^{-1}$ and 1.07-1.17 $\mathrm{g} \mathrm{cm}^{-3}$, respectively (Bienfang, 1980; Urban et al., 1993), which are considerably higher than our results (Fig. 4). We suggest that these differences might be caused by the differences in methodology used (Griffin, 2000).

To compare the combined effects of sinking and degradation rates for each treatment, the reciprocal length scale, or $\mathrm{L}$ ratio, which is the fraction of pellet degradation per unit length traveled, was calculated (Feinberg and Dam, 1998). The product of the $\mathrm{L}$ ratio multiplied by the depth of the mixed layer can then be used to provide the degree of degradation of a pellet within this layer. The results from such calculations suggest that some diets might result in pellets that are substantially recycled within the epipelagic layer whereas others result in pellets that are exported out of the mixed layer in a relatively non-degraded manner. It should be pointed out, however, that the degradation rates we calculated are likely to be highly underestimated due to the absence of zooplankton activities. For example, it has been reported that copepod ingestion of entire fecal pellets (i.e., coprophagy) or only partial breakdown of fecal pellets might dramatically reduce the overall downward transport of fecal material and thus increase its retention in the epipelagic layer (Lampitt et al., 1990; Gonzalez and Smetacek, 1994; Svensen et al., 2012). For the same reason, plus the absence of turbulence in our experimental set-up, our sinking rate measurements are likely to be overestimated. Nevertheless, the L ratio provides a relative indicator of the export efficiency of the fecal pellets produced on diatom diets of different silica content and can be used for a comparison with copepod fecal pellets 
produced with other diets. Our results also show that pellets produced from high-silica-content diatoms are more likely to sink out of the mixed layer before being degraded, when compared with pellets from low-silica-content diatoms. On the other hand, fecal pellets produced from a low concentration of prey with low-silica content are the most likely to be degraded in the mixed layer (Table 3). Our results suggest that the grazing activity of copepods might result in organic matter being mostly recycled in the mixed layer during the fast-growth period of diatoms (e.g., at the beginning of the bloom), whereas it could accelerate the export of POC to the deep ocean by producing fast-sinking fecal pellets during the slow-growth period of diatoms (e.g., during the senescent stage of the diatom bloom).

In conclusion, the silica content of the cell wall of diatoms can affect the grazing activity of copepods and influence the rates of production, decomposition and sinking of their fecal pellets. Our findings suggest that it is not only the nutritional quality but also the digestion process of copepods that can result in the different characteristics of the pellets produced. In addition, it is a combination of both degradation and sinking rates (which are affected by the abundance and cellular silica content of the diatom prey among other physicochemical factors) that determines the efficiency of the downward export of biogenic silica and organic carbon by fecal pellets.

\section{The Supplement related to this article is available online at doi:10.5194/bg-13-4767-2016-supplement.}

Acknowledgements. Financial support for this study was from the Research Grant Council of Hong Kong (661610, 661911 and 661912) and the National Key Scientific Research Projects of China (2015CB954003). Additional support was provided by the TUYF Charitable Trust (TUYF10SC08).

Edited by: G. Herndl

Reviewed by: two anonymous referees

\section{References}

Armstrong, R. A., Lee, C., Hedges, J. I., Honjo, S., and Wakeham, S. G.: A new, mechanistic model for organic carbon fluxes in the ocean based on the quantitative association of POC with ballast minerals, Deep-Sea Res. Pt. II, 49, 219-236, 2002.

Ayukai, T.: Fecal pellet production by two species of planktonic calanoid copepods fed on naturally occurring particles, Bull. Plankton Soc. Japan, 37, 3-10, 1990.

Ayukai, T. and Nishizawa, S.: Defecation rate as a possible measure of ingestion rate of Calanus pacificus (Copepoda: Calanoida), Bull. Plankton Soc. Japan, 33, 3-10, 1986.

Båmstedt, U., Nejstgaard, J. C., and Solberg, P. T.: Utilisation of small-sized food algae by Calanus finmarchicus (Copepoda,
Calanoida) and the significance of feeding history, Sarsia, 84, 19-38, 1999.

Bathmann, U. V., Noji, T. T., Voss, M., and Peinert, R.: Copepod fecal pellets: abundance, sedimentation and content at a permanent station in the Norwegian Sea in May/June 1986, Mar. Ecol.-Prog. Ser., 38, 45-51, 1987.

Besiktepe, S. and Dam, H.G.: Coupling of ingestion and defecation as a function of diet in the calanoid copepod Acartia tonsa, Mar. Ecol.-Prog. Ser., 229, 151-164, 2002.

Bienfang, P. K.: Herbivore diet affects fecal pellet settling, Can. J. Fish. Aquat. Sci., 37, 1352-1357, 1980.

Bienfang, P. K.: SETCOL-A technologically simole and reliable method for measuring phytoplankton sinking rates, Can. J. Fish. Aquat. Sci., 38, 1289-1294, 1981.

Bienfang, P., Harrison, P., and Quarmby, L.: Sinking rate response to depletion of nitrate, phosphate and silicate in four marine diatoms, Mar. Biol., 67, 295-302, 1982.

Butler, M. and Dam, H. G.: Production rates and characteristics of fecal pellets of the copepod Acartia tonsa under simulated phytoplankton bloom conditions: implications for vertical fluxes, Mar. Ecol.-Prog. Ser., 114, 81-91, 1994.

Claquin, P., Martin-Jézéquel, V., Kromkamp, J. C., Veldhuis, M. J. W., and Kraay, G. W.: Uncoupling of silicon compared with carbon and nitrogen metabolisms and the role of the cell cycle in continuous cultures of Thalassiosira pseudonana (Bacillariophyceae) under light, nitrogen, and phosphorus control, J. Phycol., 38, 922-930, 2002.

Dagg, M. and Walser, W. E.: The effect of food concentration on fecal pellet size in marine copepods, Limnol. Oceanogr., 31, 10661071, 1986.

Dagg, M. J., Urban-Rich, J., and Peterson, J. O.: The potential contribution of fecal pellets from large copepods to the flux of biogenic silica and particulate organic carbon in the Antarctic Polar Front region near $170^{\circ}$ W., Deep-Sea Res. Pt. II, 50, 675-691, 2003.

Feinberg, L. R. and Dam, H. G.: Effects of diet on dimensions, density and sinking rates of fecal pellets of the copepod Acartia tonsa, Mar. Ecol.-Prog. Ser., 175, 87-96, 1998.

Fowler, S. W. and Small, L.: Sinking rates of euphausid fecal pellets, Limnol. Oceanogr., 17, 293-296, 1972.

François, R., Honjo, S., Krishfield, R., and Manganini, S.: Factors controlling the flux of organic carbon to the bathypelagic zone of the ocean, Global Biogeochem. Cy., 16, 1087, doi:10.1029/2001GB001722, 2002.

Friedrichs, L., Hörnig, M., Schulze, L., Bertram, A., Jansen, S., and Hamm, C.: Size and biomechanic properties of diatom frustules influence food uptake by copepods, Mar. Ecol.-Prog. Ser., 481, 41-51, 2013.

Frost, B. W.: Effects of size and concentration of food particles on the feeding behavior of the marine planktonic copepod Calanus pacificus, Limnol. Oceanogr., 17, 805-815, 1972.

Goldthwait, S. A. and Steinberg, D. K.: Elevated biomass of mesozooplankton and enhanced fecal pellet flux in cyclonic and modewater eddies in the Sargasso Sea, Deep-Sea Res. Pt. II, 55, 13601377, 2008.

González, H. E. and Smetacek, V.: The possible role of the cyclopoid copepod Oithona in retarding vertical flux of zooplankton fecal material, Mar. Ecol.-Prog. Ser., 113, 233-246, 1994. 
González, H. E., Menschel, E., Aparicio, C., and Barría, C.: Spatial and temporal variability of microplankton and detritus, and their export to the shelf sediments in the upwelling area off Concepción, Chile $\left(\sim 36^{\circ} \mathrm{S}\right)$, during 2002-2005, Prog. Oceanogr., 75, 435-451, 2007.

Grasshoff, K., Kremling, K., and Ehrhardt, M.: Methods of seawater analysis, Wiley-Vch, Weinheim, 1999.

Griffin, S. L.: Influence of food type on the production and setting rate of faecal pellets produced by an estuarine copepod, Mar. Freshwater Res., 51, 371-378, 2000.

Guillard, R. R. L.: Culture of phytoplankton for feeding invertebrates, in: Culture of marine invertebrates, edited by: Smith, W. L. and Chanley, M. H., Plenum Press, New York, 1975.

Hansen, B., Fotel, F. L., Jensen, N. J., and Madsen, S. D.: Bacteria associated with a marine planktonic copepod in culture, II Degradation of fecal pellets produced on a diatom, a nanoflagellage or a dinoflagellate diet, J. Plankton Res., 18, 275-288, 1996.

Herve, V., Derr, J., Douady, S., Quinet, M., Moisan, L., and Lopez, P. J.: Multiparametric analyses reveal the $\mathrm{pH}$-dependence of silicon biomineralization in diatoms, PLoS ONE, 7, 1-12, 2012.

Honjo, S. and Roman, M. R.: Marine copepod fecal pellets production, preservation and sedimentation, J. Mar. Res., 36, 45-57, 1978.

Klaas, C. and Archer, D. E.: Association of sinking organic matter with various types of mineral ballast in the deep sea: implications for the rain ratio, Global Biogeochem. Cy. 16, 1116, doi:10.1029/2001GB001765, 2002.

Komar, P. D.: Settling velocities of circular cylinders at low Reynolds numbers, J. Geol., 88, 327-336, 1980.

Lampitt, R. S., Noji, T., and Bodungen, B. V.: What happens to zooplankton fecal pellets? Implications for material flux, Mar. Biol., 104, 15-23, 1990.

Liu, H., Chen, M., Zhu, F., and Harrison, P. J.: Effect of diatom silica content on copepod grazing, growth and reproduction, Front. Mar. Sci., 3, 89, doi:10.3389/fmars.2016.00089, 2016.

Martin-Jézéquel, V., Hildebrand, M., and Brzezinski, M. A.: Silicon metabolism in diatoms: implications for growth, J. Phycol., 36, $821-840,2000$
Olesen, M., Strake, S., and Andrushaitis, A.: Egestion of non-pelletbound fecal material from the copepod Acartia tonsa: implication for vertical flux and degradation, Mar. Ecol.-Prog. Ser., 293, 131-142, 2005.

Paasche, E.: Silicon content of five marine plankton diatom species measured with a rapid filter method, Limnol. Oceanogr., 25, 474480, 1980.

Pondaven, P., Gallinari, M., Chollet, S., Bucciarelli, E., Sarthou, G., Schultes, S., and Jean, F.: Grazing-induced changes in cell wall silicification in a marine diatom, Protist, 158, 21-28, 2007.

Poulsen, L. K. and Iversen, M. H.: Degradation of copepod fecal pellets: key role of protozooplankton, Mar. Ecol.-Prog. Ser., 367 , 1-13, 2008.

Shek, L. and Liu, H.: Oxygen consumption rates of fecal pellets produced by three coastal copepod species fed with a diatom Thalassiosira pseudonana, Mar. Pollut. Bull., 60, 1005-1009, 2010.

Svensen, C., Riser, C. W., Reigstad, M., and Seuthe, L.: Degradation of copepod faecal pellets in the upper layer: role of microbial community and Calanus finmarchicus, Mar. Ecol.-Prog. Ser., 462, 39-49, 2012.

Turner, J. T.: Sinking rates of fecal pellets from the marine copepod Pontella meadii, Mar. Biol., 40, 249-259, 1977.

Turner, J. T.: Zooplankton fecal pellets, marine snow and sinking phytoplankton blooms, Aquat. Microb. Ecol., 27, 57-102, 2002.

Turner, J. T.: Zooplankton fecal pellets, marine snow, phytodetritus and the ocean's biological pump, Prog. Oceanogr., 130, 205-248, 2015.

Urban, J. L., Deibel, D., and Schwinghamer, P.: Seasonal variations in the densities of fecal pellets produced by Oikopleura vanhoeffeni (C. Larvacea) and Calanus finmarchicus (C. Copepoda), Mar. Biol., 117, 607-613, 1993.

Vrieling, E. G., Sun, Q., Tian, M., Kooyman, P. J., Gieskes, W. W., van Santen, R. A., and Sommerdijk, N. A. J. M.: Salinitydependent diatom biosilicification implies an important role of external ionic strength, P. Natl. Acad. Sci USA, 104, 1044110446, 2007. 